\title{
Öğrencilerde Çok Boyutlu Mükemmeliyetçilik Algısının Benlik Saygısı ve Stres ile İncelenmesi*
}

\author{
Investigation of Students' Perceptions of Multidimensional \\ Perfectionism with Self-Esteem and Stress \\ Mine AYDEMIR ${ }^{1}$, Nuran BAYRAM ARLI ${ }^{2}$
}

• Geliş Tarihi: 09.03.2019 • Kabul Tarihi: 12.07.2019 • Çevrimiçi Yayın Tarihi: 15.07.2019

\section{Öz}

Bireylerin en iyiye ulaşma süreci içinde yaşadığı duygudurumlarının bir göstergesi olan mükemmeliyetçilik algısı; depresyon, anksiyete, stres, tükenmişlik vb. için bir risk faktörü olarak görülmektedir. Diğer yandan ise mükemmeliyetçilik algısının bazı boyutlarıyla pozitif olarak değerlendirilebileceği düşünülmektedir. Bu noktadaki tartışmalardan yola çıkarak mevcut çalışmada mükemmeliyetçilik alt boyutlarının, olumlu ve olumsuz olarak değerlendirilebilecek kavramlar üzerindeki etkilerinin, benzer olup olmayacağı sorusu incelenmiş ve üniversite öğrencileri örneklemi için alt boyutların etkisinin hangi yönde olacağına dair çıkarımlar elde etmek amaçlanmıştır. Bu amaçla olumlu ve olumsuz olarak sırasıyla benlik saygısı ve stres değişkenleri ele alınmış ve mükemmeliyetçilik alt boyutları ile ilişkileri modellenmiştir. Çalışmada ölçüm hatalarını da hesaba katarak daha güçlü tahmin sonuçları üreten yapısal eşitlik modelleri ile tahminler yapılmıştır. Bu çalışma ile üniversite öğrencilerin mükemmeliyetçilik algılarının stres ve benlik saygısı üzerinde istatistiksel olarak anlamlı etkilere sahip olduğu bulgusunun yanı sıra bazı mükemmeliyetçilik alt boyutları için benlik saygısının aracılık etkisi gösterdiği ortaya konulmuştur. Analizler sonucunda mükemmeliyetçiliğin dört boyutunun stres üzerinde, tüm boyutlarının ise benlik saygısı üzerinde direk etkisi olduğu sonuçları elde edilmiştir. Bu çalışmanın bulguları daha önceki çalışmalarda elde edilen sonuçlarla desteklenmesinin yanı sıra mevcut örneklem için mükemmeliyetçiliğin tek boyutlu yapısından ziyade çok boyutlu yapısının daha fazla bilgi içerdiğine yönelik kanıtlar sunmuştur.

Anahtar sözcükler: benlik saygısı, çok boyutlu mükemmeliyetçilik, stres, yapısal eşitlik modellemesi

Atıf:

Aydemir, M. ve Bayram Arlı, N. (2020). Öğrencilerde Çok Boyutlu Mükemmeliyetçilik Algısının Benlik Sayıs1 ve Stres ile İncelenmesi. Pamukkale Üniversitesi Ĕgitim Fakültesi Dergisi, 48, 252270.10.9779/pauefd.537739

\footnotetext{
* Bu çalışma I. International Conference on Social Sciences'da özet bildiri olarak sunulmuştur.

1 Arş. Gör., Uludağ Üniversitesi, İIBBF, Ekonometri Bölümü, mineaydemir@uludag.edu.tr, https://orcid.org/00000003-3276-8148

$\frac{1}{2}$ Prof. Dr., Uludağ Üniversitesi, İ̈BF, Ekonometri Bölümü, nuranb@uludag.edu.tr, https://orcid.org/0000-0001$\underline{5492-184 X}$
} 


\begin{abstract}
Perfectionism can be considered as an indicator of the emotions of individuals in the process of reaching the best. Perfectionism is seen as a risk factor for negative emotions such as depression, anxiety, stress, and burnout. On the other hand, it is thought that the perception of perfectionism can be considered positive with some dimensions. Based on the discussions at this point, the question of whether the effects of perfectionism dimensions on the concepts that can be evaluated as positive and negative are examined in the current study. It is aimed to make inferences about the direction of perfectionism sub-dimensions. Estimations were made with structural equation models that produced stronger estimation results by taking into account measurement errors. As a result of this study, it was found that university students' perceptions of perfectionism had statistically significant effects on stress and self-esteem. At the same time, it has been shown that self-esteem is mediating for some perfectionism sub-dimensions. It was found that the four dimensions of perfectionism directly affected stress and also all dimensions directly affected self-esteem. At the same time, these findings provide evidence that the multidimensional structure rather than the one-dimensional structure of perfectionism contains more information.
\end{abstract}

Keywords: multidimensional perfectionism, self-esteem, stress, structural equation modeling

\title{
Cited:
}

Aydemir, M. \& Bayram Arlı, N. (2020). Investigation of students' perceptions of multidimensional perfectionism with self-esteem and stress. Pamukkale Üniversitesi Eğitim Fakültesi Dergisi, 48, 252-270. 10.9779/pauefd.537739 


\section{Giriş}

İnsan davranışları ve bu davranışların nedenlerinin incelenmesi birçok disiplinin ilgisini çekmektedir. İnsan davranışının anlaşılması, ilgili sorunlara çözüm üretilmesi ve süreçlerin iyileştirilmesi açısından oldukça önemlidir. Özellikle kişinin kendisine karşı davranışları ele alındığında ilk akla gelen kavramlardan biri mükemmeliyetçilik olmaktadır. Kişinin en iyiye ulaşma isteği ile yakından ilişkili olan bu kavram incelenmesi gereken önemli bir konudur.

Mükemmeliyetçilik yüksek kişisel beklentilere eğilimli olma ya da mükemmel performansın önemine yönelik tutumlar şeklinde tanımlanmıştır (Burns, 1980). Mükemmeliyetçilik kavramı kişiliğin bir parçası olarak ele alınmıştır (Hamachek, 1978; Hollender, 1965). Adler (1956) mükemmeliyetçiliğin doğuştan geldiğini aynı zamanda pozitif ve negatif olarak iki yönlü değerlendirilebileceğine odaklanmıştır. Hamachek (1978) mükemmeliyetçiliği normal ve nevrotik olarak iki şekilde ele almıştır. Burns (1980) mükemmeliyetçiği bilişsel bir yapı olarak düşünmüş ve çok boyutlu olarak tanımlamaya çalışmıştır. İlerleyen dönemlerde yapılan araştırmalarda (Frost vd., 1990; Hewitt ve Flett, 1991) mükemmeliyetçilik daha geniş yaklaşımlarla ele alınmıştır. Frost ve diğerleri (1990) mükemmeliyetçiliği Düzen, Hatalara Aşırı İlgi, Davranışlardan Şüphe, Ailesel Beklentiler, Ailesel Eleştiriler ve Kişisel Standartlar şeklinde altı farklı boyutta incelemiştir (Bieling vd., 2004; Flett vd., 1991; Frost vd., 1990, s. 455; Özbay ve Misırl1-Taşdemir, 2003; Hawkins vd., 2006). Hewitt ve Flett (1991) ise mükemmeliyetçiliği kendine yönelik, başkalarına yönelik ve sosyal düzene yönelik olmak üzere üç farklı boyutta değerlendirmiştir. Bu çalışmada altı farklı mükemmeliyetçilik boyutu içeren ve Frost ve diğerleri (1990) tarafından geliştirilen çok boyutlu mükemmeliyetçilik yaklaşımı kullanılmıştır. Bu boyutlar kısaca aşă̆ıdaki gibi özetlenebilir (Frost vd., 1990, s. 450-451);

$\checkmark$ Düzen, mükemmeliyetçi kişi titizlik, dakiklik ve düzenlilik kavramlarını aşırı vurgular.

$\checkmark$ Hatalara aşırı ilgi, mükemmeliyetçi kişi performansının mükemmel olmasına odaklanır ve aksi durumda her küȩük kusuru başarısızlık olarak değerlendirir.

$\checkmark$ Davranışlardan şüphe, kişi performansının niteliğinden emin olamaz.

$\checkmark$ Ailesel beklenti, kişi sevgi ve onay için mükemmel olmak zorunda hisseder.

$\checkmark$ Ailesel eleştiri, kişinin gerçekçi olmayan beklentilere sahip ve eleştirel ebeveynlere sahip olması sebebiyle yaşadı̆̆ 1 histir.

$\checkmark$ Kişisel standartlar, kişi kendine yüksek düzeyde performans standartları belirler.

Mevcut ölçüm araçları üzerinden mükemmeliyetçiliğin boyutlarının nasıl olması gerektiği ile ilgili çalışmalar yapılmıştır. Stallman ve Hurst'ın (2011) çalışmasında mükemmeliyetçiliğin boyutları tartışılmıştır. Öğrencilerin mükemmeliyetçiliğinin anlaşılması için öncelikle mükemmeliyetçilik kavramının faktör yapısının anlaşılması gerektiğine değinmişlerdir. Çalışmalarında mükemmeliyetçiliğin beş boyutlu bir yapı gösterdiğini ortaya koymuşlardır. Frost ve digerlerinden (1990) farklı olarak ailesel eleştiri ve ailesel beklentiler boyutları tek bir boyut olarak birleştirilmiştir. Hawkins ve diğerleri, (2006) mükemmeliyetçiliği dört boyutlu bir 
yap1 olarak yeniden formüle etmişlerdir. Ailesel eleştiri ve ailesel beklentileri bir boyut olarak ele alırken davranışlardan şüphe ve hatalara aşırı ilgiyi bir boyut olarak değerlendirmişler ve dört boyutlu bir yapı önermişlerdir. Kişisel standartlar ve düzen boyutunu pozitif mükemmeliyetçilik olarak, davranışlardan şüphe \& hatalara aşırı ilgi ve ailesel eleştiri \& ailesel beklenti boyutlarını ise negatif mükemmeliyetçilik olarak değerlendirmişlerdir.

Zaman içinde yapılan çalışmalarla mükemmeliyetçiliğin çok boyutlu yapısı ortaya konulmuştur. Yapılan çalışmaların (Cheng vd., 1999; Cox vd., 2002; D'Souza vd., 2011; Frost vd., 1990; Hawkins vd., 2006; Rice vd., 1998; Saboonchi ve Lundh, 1997; Stallman ve Hurst, 2011) sonuçları mükemmeliyetçiliğin çok boyutlu olduğunu ve hem pozitif hem negatif boyutlar içerdiğini göstermiştir. Bu tartışmalar ve yapılan çalışmalar mükemmeliyetçiliğin adaptif (uyumlu/olumlu/sağlıklı) ve maladaptif (uyumsuz/olumsuz/sağlıksız) yönelimlerini ortaya koymuştur. Adaptif mükemmeliyetçilik kişinin daha iyiye yönelmesi, kendine yüksek hedefler belirlemesi ve bu süreçleri sağlıklı bir şekilde yürütmesini ifade etmektedir. Diğer yandan maladaptif mükemmeliyetçilik ise kişinin bu süreçleri sağlıklı şekilde yürütemediğini, hedeflere ulaşmak için gerçekçi olmayan standartlar uyguladığını ve takıntılı boyutlara ulaşan durumları göstermektedir (Cheng vd., 1999; Cox vd., 2002; D'Souza vd., 2011; Frost vd., 1990; Rice vd., 1998; Saboonchi ve Lundh, 1997; Stallman ve Hurst, 2011). Bu noktada süregelen çalışmalar mükemmeliyetçiliğin tek boyutlu ve çok boyutlu yapısını ortaya koymanın yanı sıra çok boyutlu yapının getirdiği yeni bakış açısıyla mükemmeliyetçiliğin bazı noktalarda yararlı bazı noktalarda ise yararlı olmadığını öne sürmektedir. Bu noktadaki tartışmalardan yola çıkarak farklı mükemmeliyetçilik boyutlarının, olumlu ve olumsuz olarak değerlendirilebilecek kavramlar üzerindeki etkilerinin farklı örneklemlerde benzer olup olmayacağı sorusu akla gelmektedir.

Frost ve diğerleri (1990) çok boyutlu mükemmeliyetçilik ölçeğini geliştirdikleri çalışmalarında ölçeğin alt boyutları ve toplam mükemmelliyetçilik ile depresyon arasındaki ilişkileri incelemişlerdir. Toplam mükemmelliyetçilik ile depresyon arasında pozitif ve anlamlı korelasyon gözlenmiştir. Aynı şekilde anksiyete ile de pozitif anlamlı ilişki gözlenmiştir. Boyutlar ile depresyon arasındaki ilişkiler incelendiğinde hatalara aşırı ilgi ile depresyon ve anksiyete arasında pozitif ve anlamlı ilişki, davranışlardan şüphe ile depresyon ve anksiyete arasında yine pozitif ve anlamlı ilişkiler gözlenmiştir (Frost vd., 1990, s. 460). Frost ve diğerleri (1993) çok boyutlu yapının ailesel eleştiri ve beklenti, hatalara aşırı ilgi ve davranışlardan şüphe boyutlarını maladaptif boyutlar (maladaptive evaluation concerns) olarak, kişisel standartlar ve düzen boyutlarını ise olumlu çabalar (positive striving) olarak değerlendirmişlerdir. Olumlu çabalar olarak değerlendirilen bu boyutlarla depresyon arasında anlamlı ilişkiler bulunmazken maladaptif boyutlarla depresyon arasında anlamlı ilişkiler bulunmuştur (Frost vd., 1993, s. 124). Saboonchi ve Lundh (1997), mükemmelliyetçilik boyutları ile sosyal anksiyete arasındaki ilişkileri araştırdığı çalışmada mükemmeliyetçiliğin iki boyutu olan hatalara aşırı ilgi ve davranışlardan şüphe ile sosyal anksiyete arasında anlamlı ilişkiler bulmuştur. Diğer boyutlar ile sosyal anksiyete arasında anlamlı ilişkiler bulunamamıştır (Saboonchi ve Lundh, 1997, s. 924).

Rice ve diğerleri (1998) yapısal eşitlik modeli kurarak araştırdıkları maladaptif mükemmeliyetçilik ve depresyon arasındaki ilişkide benlik saygısının aracılık etkisi olduğunu tespit etmişlerdir. Mükemmeliyetçilik depresyonu benlik saygısı üzerinden dolaylı ve negatif olarak etkilerken direk etkisi pozitif olarak gerçekleşmektedir. Benlik saygısı üzerindeki etkisi 
ise negatiftir. Bu bulgu Horney'in (1950) "Mükemmeliyetçi birey için düşük benlik saygıs1 kaçınılmazdır" tespiti ile örtüşmektedir. Adaptif mükemmeliyetçiliğin direk ya da dolaylı olarak depresyon üzerinde etkisi tespit edilmemiştir (Rice vd., 1998, s. 305, 310). Cheng ve diğerlerinin (1999) çalışmasında anksiyete, stres ve depresyon ile mükemmeliyetçilik arasındaki ilişkileri araştırmıştır. Mükemmeliyetçilik tek boyut olarak ele alınmış ve bu üç değişken ile aralarında anlamlı ve pozitif ilişki gözlenmiştir. Aynı çalışmada benlik saygısı ile mükemmeliyetçilik ilişkisi negatif bulunmuştur. Mükemmeliyetçiliğin boyutlarından düzen ile anksiyete ve depresyon arasında negatif anlamlı ilişki gözlenmiş ancak stres ile bu boyut arasında anlamlı ilişki bulunamamıştır. Diğer tüm mükemmeliyetçilik boyutları ile anksiyete, stres ve depresyon arasında anlamlı pozitif ilişki bulunmuştur (Cheng vd., 1999, s.1057). Bu noktada Hollender'in (1965) belirttiği gibi mükemmeliyetçi birey tam bir tatmin ya da memnuniyet duygusu yaşamadığı için bu durum kendini stres ve depresyon olarak gösterebilir (Rice vd., 1998, s. 305). D'Souza ve diğerleri (2011) Frost'un çok boyutlu mükemmelliyetçilik ölçeğini kullanmış ve mükemmelliyetçiliği ayrı ayrı boyutlarıyla değil toplam ele alarak stres ile arasındaki ilişkileri incelemiştir. Mükemmelliyetçiliğin stresi pozitif ve anlamlı şekilde etkilediğini bulmuşlardır (D'Souza vd., 2011, s.22-23). Blatt (1995) ve Hamacnek (1978) mükemmeliyetçiliğin farklı boyutlarının kavramlar üzerinde farklı roller oynayabileceğini, özellikle zihinsel sağlık durumlarını direk etkilemekten ziyade bu etkinin benlik saygısı aracılığıyla gerçekleşebileceğini belirtmişlerdir (Rice vd., 1998, s. 305). Bu tespit mükemmeliyetçiliğin farklı boyutlarının etkilerinin de farklı olabileceğini vurgulamaktadır.

Stres, anksiyete, depresyon ve tükenmişlik gibi kavramlar insan için olumsuz kavramlar olarak değerlendirilmektedir. Mükemmeliyetçiliğin stres, anksiyete, tükenmişlik gibi kavramlar için bir risk faktörü olduğu düşünülmekte ve amprik çalışmaların sonuçları bu düşünceyi desteklemektedir. Bunun tersi bir şekilde mükemmeliyetçiliğin alt boyutlardan olan yüksek kişisel standartlar oluşturma ve düzen ise olumlu değerlendirilmekte ve sağliklı yaşantılarla ilişkilendirilmektedir (Cheng vd., 1999; D'Souza vd., 2011; Frost vd., 1993; Özbay ve Misırl1Taşdemir, 2003; Rice vd., 1998; Smith vd., 2016). Chang ve arkadaşlarının (2004) çalışmasında adaptive mükemmeliyetçilik ile algılanan stres arasında anlamlı ilişki bulunmazken maladaptive mükemmeliyetçilik ile algılanan stres arasında anlam ve pozitif ilişki bulunmuştur. Diğer bir çalışmada Bieling ve diğerleri (2004) stres ile maladaptive adaptive mükemmeliyetçilik arasında anlamlı pozitif ilişki bulmuştur. Bir diğer çalışmada Ashby ve arkadaşları (2012) adaptive mükemmeliyetçilik ile algılanan stresi negatif ilişkili bulunurken, maladaptive mükemmeliyetçilik ile algılanan stresi pozitif ilşkili bulmuşlardır. $\mathrm{Bu}$ bilgiler 1şığında mükemmeliyetçilik kavramının adaptif ve maladaptif olarak ele alındığ 1 ve farklı bir yaklaşımla değerlendirildiği görülmektedir. Bu durumda mükemmeliyetçilik kişiye fayda sağlayabilir ya da kendine fazla yüklenmesiyle beraber zor psikolojik süreçlerin içine sürükleyebilir. Bieling ve diğerlerinin (2004) çalışmasında değindiği gibi mükemmeliyetçiliğin adaptif ve maladaptif olarak kavramsallaştırılması mevcut ölçeklerin pozitif ve negatif bileşenlerinin dikkatlice incelenmesi ile test edilebilir. Yapılan çalışmalar mükemmeliyetçiliğin nasıl daha iyi tanımlanacağı noktasında, üniter bir yapı olarak mı yoksa adaptif ve maladaptif olarak iki boyutlu mu olması gerektiği sorusuna netlik getirememişlerdir (Bieling vd., 2004, s.1376). 
$\mathrm{Bu}$ çalışmada diğer çalışmalardan farklı olarak Frost ve diğerleri (1990) tarafindan geliştirilen ve mükemmeliyetçiliği birçok yönüyle ele alan çok boyutlu mükemmeliyetçilik ölçeğinin alt boyutlarının ayrı ayrı ele alınarak ilişkili değişkenlerle modellenmesi amaçlanmıştır. Her bir alt boyutun, ele alınan değişkenlerle ilişkisi incelenerek aynı zamanda mükemmeliyetçilik ölçeğinin alt boyutlarına ilişkin işleyiş hakkında bilgi vermesi beklenmiştir. Mükemmeliyetçilik kavramının birlikte ele alındığı değişkenler; benlik saygısı ve stres değişkenleridir. Bu iki değişkenin çalışmaya dahil edilmesinin iki sebebi vardır. İlki çalışmaya bir olumlu bir olumsuz ve mükemmeliyetçiliğin üzerinde etkili olabileceği düşünülen iki değişken dahil edilmek istenmiş ve bu sebeple stres olumsuz, benlik saygisı ise olumlu kavramlar olarak alınmıştır. Bu kavramların seçilmesinin ikinci sebebi ise her iki kavramın da literatürde çokça ele alınması ve değişkenlerle ilgili birçok sonucun rapor edilmiş olmasıdır. Buradaki amaç olumlu (benlik saygısı) ve olumsuz (stres) iki değişken ile birlikte mükemmeliyetçiliğin alt boyutlarının ayrı ayrı ele alınması ve pozitif/negatif etkilerin mevcut örneklemde ölçüm hatalarını da hesaba katarak daha güvenilir tahmin sonuçları üreten yapısal eşitlik modelleri ile ortaya konulmasıdır. Türkiye'de mükemmeliyetçilik kavramı ile ilgili yapılan çeşitli çalışmalar bulunmakla beraber (Camadan ve Yüksel, 2012; Çam vd., 2014; Kağan, 2011; Leana-Tascilar ve Kanli, 2014; Mert, 2019; Özgüngör, 2003) çok boyutlu mükemmeliyetçiliğin (Frost vd., 1990) alt boyutları ve bunların bireysel etkileri (benlik saygısı, stres) üzerine detaylı bir çalışmaya rastlanmamıştır.

Mevcut çalışmanın temel amaçları;

$\checkmark$ Literatürde yapısı ve alt boyutları ile ilgili tartışmalar devam eden mükemmeliyetçilik ölçeğinin alt boyutlarının ayrı ayrı ele alınarak incelenmesi,

$\checkmark$ Mükemmeliyetçiliğin her bir alt boyutunun belirlenen iki değişken (benlik saygısı ve stres) üzerindeki etkilerinin yapısal eşitlik modellemesi ile incelenmesi,

$\checkmark$ Mükemmeliyetçilik ölçeğin alt boyutlarının kendi içinde, literatürde tartışıldığ gibi, adaptif ve maladaptif eğilim gösterip göstermediğine dair kanıtların varlığının araştırılması,

$\checkmark$ Mükemmeliyetçilik ölçeğinin farklı sayıda alt boyut ile kullanılmasını öneren çalışmaların sonuçlarını destekler kanıtların oluşup oluşmadığının incelenmesi,

$\checkmark$ Mükemmeliyetçilik alt boyutları ile kurulan modellerde benlik saygısı ve stres ile ilişkilerin modellenerek aracılık etkisinin varlığının araştırılması,

olarak sıralanmaktadır

\section{Yöntem}

\section{Çalışma Grubu}

Araştırmaya bir kamu üniversitesinde okuyan 394 üniversite öğrencisi gönüllü olarak katılmıştır. Bu çalışmanın örneklemi sadece üniversite öğrencileriyle sınırlıdır. Araştırmanın örneklemi kolayda örnekleme yöntemi ile oluşturulmuştur. Önceden bilgilendirilen katılımcılar demografik sorular ve ölçeklerden oluşan bir anket formunu cevaplamışlardır. 394 form arasından hatalı ve eksik olanlar elenmiştir. Eksiksiz geri dönüş alınan toplam 367 form 
üzerinden yürütülen çalışmanın örneklemi 222 kadın öğrenci ve 145 erkek öğrenciden oluşmaktadır. Öğrenciler 18-28 yaş arasında yer almaktadır ve tüm örneklem için yaş ortalaması $21.81( \pm 2.37)$ olarak bulunmuştur.

\section{Çalışmada Kullanılan Ölçme Araçları}

Mükemmeliyetçilik kavramını ölçmek için Frost ve diğerleri (1990) tarafından geliştirilen Çok Boyutlu Mükemmeliyetçilik Ölçeği (Frost Multidimensional Perfectionism Scale) kullanılmıştır. $\mathrm{Bu}$ ölçek mükemmeliyetçiliği birçok yönüyle değerlendirmektedir. Çok Boyutlu Mükemmeliyetçilik ölçeği 35 soru ve 6 boyuttan oluşmaktadır. Maddelerin değerlendirilmesinde 1'den (Kesinlikle katılmıyorum) 5'e (Kesinlikle katılıyorum) doğru beşli likert kullanılmaktadır. Orijinal çalışmada alt boyutların güvenilirlik katsayıları 0.77 ile 0.93 arasında değişmektedir. Ölçeğinin tamamı için hesaplanan güvenilirlik katsayısı ise 0.90 'dır. Ölçekten alınan yüksek puanlar mükemmeliyetçiliğin yüksek olduğunu göstermektedir Ölçeğin Türkçe uyarlama çalışmaları Özbay ve Mısırlı-Taşdemir (2003) tarafından yapılmıştır. Uyarlanmış çalışmada ölçeğin toplam madde sayısı ve boyutları korunmuştur. Ölçek orijinalindeki gibi altı boyuta sahiptir ve bu boyutlar şöyle isimlendirilir; Düzen (D), Hatalara Aşırı İlgi (HAİ), Davranışlardan Şüphe (DŞ), Ailesel Beklenti (AB), Ailesel Eleştiri (AE) ve Kişisel Standartlar (KS). Ölçeğin alt boyutlarının ayrı ayrı hesaplanmasının yanı sıra mükemmeliyetçilik toplam puan olarak da hesaplanabilmektedir. Uyarlanan çalışmada boyutların güvenilirlik katsayıları 0.61 ile 0.87 arasında yer alırken ölçeğin toplam güvenilirlik katsayısı 0.83 olarak hesaplanmıştır. Frost ve diğerleri (1990) toplam puan hesaplanırken düzen boyutunun dışarıda bırakılması gerektiğini belirtmişlerdir (Frost vd., 1990, s. 454, Frost vd., 1993; Özbay ve Misırl1-Taşdemir, 2003).

Stres kavramını ölçmek için Lovibond ve Lovibond (1995) tarafından geliştirilen DASS (Depression, Anxiety and Stress Scale) Ölçeği'nin Stres alt boyutu kullanılmıştır. Ölçeğin Türkçe uyarlama çalışması Bilgel ve Bayram (2009) tarafindan yapılmıştır. Stres boyutunun güvenilirlik katsayısı orijinal çalışmada 0.90 uyarlanan çalışmada 0.88 olarak hesaplanmıştır. Üç boyut içeren (Depresyon, Anksiyete, Stres) ölçekteki boyutlar ayrı ayrı kullanmak için de uygundur. Bu nedenle çalışmada kullanılmak üzere 14 sorudan oluşan stres boyutu alınmıştır. Ölçekteki maddeler 4'lü likert (0-Hiç katılmıyorum ... 3-Tamamen katılıyorum) ile ölçülmektedir. Ölçekten alınan yüksek puanlar stresin yüksek olduğunu göstermektedir (Bilgel ve Bayram, 2009).

Benlik saygısının ölçülmesi için Rosenberg (1965) tarafından geliştirilen Benlik Saygısı Ölçeği (Rosenberg Self Esteem Scale) kullanılmıştır. Ölçeğin Türkçe güvenilirlik çalışmas1 Çuhadaroğlu (1985) tarafından yapılmıştır. Ölçek toplam 10 sorudan oluşmaktadır. Orijinal ölçeğin güvenilirlik değeri 0.92 olarak elde edilirken uyarlanan çalışmada güvenilirlik değeri 0.86 'dır. Benlik saygısı ölçeğinden alınan yüksek puanlar kişinin benlik saygısının yüksek olduğunu göstermektedir (Çuhadaroğlu, 1985).

\section{Hipotezler}

$\mathrm{Bu}$ çalışmanın tüm hipotezleri yapısal eşitlik modellemesindeki oklar ile gösterilmektedir. Araştırmaya ilişkin genel hipotezler aşağıdaki gibi ifade edilmiştir; 
$\mathrm{H}_{1}$ : Mükemmeliyetçilik algısı stresi etkilemektedir.

$\mathrm{H}_{2}$ : Mükemmeliyetçilik algısı benlik saygısını etkilemektedir.

$\mathrm{H}_{3}$ : Benlik saygis1 stresi etkilemektedir.

Ayrı ayrı modeller kurularak ele alınan mükemmeliyetçilik alt boyutlarına göre Hatalara Aşırı İlgi, Davranışlardan Şüphe, Ailesel Eleştiri ve Ailesel Beklenti boyutlarının benlik saygısını negatif yönde etkilemesi, Düzen ve Kişisel Standartlar boyutlarının ise Benlik Saygısını pozitif yönde etkilemesi beklenmektedir. Mükemmeliyetçiliğin tüm boyutlarının Stresi negatif yönde etkilemesi ve son olarak Benlik Saygısının Stresi negatif yönde etkilemesi beklenmektedir.

\section{Analizler}

Araştırma bulgularının elde edilmesi için IBM-SPSS Statistics 21 paket programından yararlanılmıştır. İlk başta toplanan 394 anket formu içerisinde yer alan eksik ve hatalı cevaplar içeren 27 anket formu elenmiştir. Geriye kalan 367 anket formunda eksik veri bulunmadığından çalışma bu örneklem üzerinden yürütülmüştür. Çalışmada kullanılan ölçeklerin iç tutarlılığını hesaplamak için Cronbach Alfa değerleri kullanılmıştır. Değişkenler için ortalamalar ve standart sapmalar dahil olmak üzere tanımlayıcı istatistikler hesaplanmıştır. Çalışmada ele alınan Çok Boyutlu Mükemmeliyetçilik ölçeğinin her bir boyutuyla, Stres ve Benlik saygısı arasındaki ilişkileri incelemek amacıyla yapısal eşitlik modelleri oluşturularak bu modeller AMOS 22 programı aracılığıyla analizi edilmiştir.

\section{Bulgular}

Çalışmaya 367 üniversite öğrencisi gönüllü olarak katılmıştır. Bunların \%60.5'i kadın, \%39.5'i erkek öğrencilerden oluşmaktadır. Örneklemin yapısı hakkında bilgi vereceği düşünülen değişkenlere ilişkin betimsel istatistikler Tablo 1'de yer almaktadır.

Tablo 1: Betimsel İstatistikler

\begin{tabular}{lll}
\hline Değişkenler & Frekans & Yüzde \\
\hline Cinsiyet & 222 & 60.5 \\
$\quad$ Kadın & 145 & 39.5 \\
$\quad$ Erkek & 234 & \\
\hline Ekonomik Durum & 63.8 \\
$\quad$ Orta ve altı & 133 & 36.2 \\
$\quad$ İyi ve üstü & & \\
\hline Algilanan Ebeveyn Tutumu & 150 & 40.9 \\
$\quad$ İlgili & 89 & 24.3 \\
Koruyucu & 40 & 10.9 \\
Demokratik & 40 & 10.9 \\
Serbest & 48 & 13.0 \\
Diğer & & \\
\hline
\end{tabular}

Öğrencilerin yaklaşı \%63'ü ekonomik durumlarının orta ve altı düzeyde olduğunu belirtmişlerdir. Bununla birlikte yaklaşık \%40’1 ebeveynlerinin ilgili tutuma, \%24'ü 
ebeveynlerinin koruyucu tutuma, \%10'u ebeveynlerinin demokratik ve serbest tutuma sahip olduğunu bildirmişlerdir. Bu örneklemden elde edilen sonuçlar doğrultusunda ilgili ve koruyucu tutuma sahip olan ailelerin çoğunlukta olduğu görülmektedir ve bu iki tutumu gösteren ailelerin sayısı örneklemin \%65.2'sine denk gelmektedir.

Çalışmada kullanılan Mükemmeliyetçilik, Stres ve Benlik Saygısı ölçeklerine ilişkin ortalama, standart sapma ve güvenilirlik katsayıları ile ilgili bilgiler Tablo 2'de özetlenmiştir.

Tablo 2: Ortalama, Standart sapma ve Cronbach's Alfa Değerleri $(\mathbf{N}=367)$

\begin{tabular}{l|l|c|c|c}
\hline Ölçekler & Boyutlar & $\begin{array}{c}\text { Madde } \\
\text { sayıs1 }\end{array}$ & Ortalama \pm Std.Sapma & Cronbach Alfa \\
\hline & Düzen & 6 & $22.75 \pm 4.63$ & 0.86 \\
& Hatalara aşırı ilgi & 9 & $23.66 \pm 6.38$ & 0.79 \\
Çok Boyutlu & Davranı̧lardan şüphe & 5 & $12.83 \pm 3.72$ & 0.74 \\
Mükemmeliyetçilik & Ailesel beklentiler & 5 & $13.50 \pm 4.13$ & 0.77 \\
& Ailesel eleştiri & 4 & $8.14 \pm 3.40$ & 0.75 \\
& Kişisel standartlar & 6 & $19.31 \pm 4.14$ & 0.75 \\
\hline DASS & Stres & 14 & $16.74 \pm 7.99$ & 0.88 \\
\hline Benlik Saygısı & Benlik Saygısı & 10 & $31.28 \pm 5.05$ & 0.84 \\
\hline
\end{tabular}

Tablo 2'deki özet sonuçlar incelendiğinde ölçeklerin güvenilirlik katsayı olan Cronbach Alfa değerlerinin tüm boyutlar için 0.70 'in üzerinde olduğu dolayısıyla ölçeklerin ve alt boyutlarının içsel olarak tutarlılık gösterdiği görülmektedir.

Mükemmeliyetçiliğin alt boyutları, Stres ve Benlik Saygısı arasındaki ilişkiler ise Tablo 3 'te gösterilmektedir.

Tablo 3: Değişkenler Arasındaki Korelasyonlar

\begin{tabular}{llllllll}
\hline & Benlik SaygiS1 & \multicolumn{1}{c}{ Stres } & AB & D & AE & HAİ & KS \\
\hline Stres & $-.25^{* *}$ & - & & & & & \\
AB & $-.16^{* *}$ & $.14^{* *}$ & - & & & & \\
D & $.31^{* *}$ & .06 & .05 & - & & & \\
AE & $-.48^{* *}$ & $-.22^{* *}$ & $.55^{* *}$ & $-.15^{* *}$ & - & & \\
HAİ & $-.36^{* *}$ & $.32^{* *}$ & $.47^{* *}$ & $.12^{*}$ & $.47^{* *}$ & - & \\
KS & $.15^{* *}$ & $.20^{* *}$ & $.34^{* *}$ & $.36^{* *}$ & $.13^{*}$ & $.46^{* *}$ & - \\
DŞ & $-.49^{* *}$ & $.33^{* *}$ & $.32^{* *}$ & .05 & $.48^{* *}$ & $.58^{* *}$ & $.21^{* * *}$ \\
\hline
\end{tabular}

Not: AB: Ailesel Beklentiler; D: Düzen; AE: Ailesel Eleş̧iri; HAİ: Hatalara Aşırı İlgi; KS: Kişisel Standartlar; DŞ: Davranışlardan Şüphe ${ }^{*} \mathrm{p}<.05,{ }^{* *} \mathrm{p}<.01$

$\mathrm{Bu}$ çalışmadaki ikili korelasyonların literatürde elde edilen sonuçlarla benzer olduğu görülmektedir (Bieling vd., 2004; Frost vd., 1990; Rice, vd., 2007; Saboonchi ve Lundh, 1997; Stumpf ve Parker, 2000; Hawkins vd., 2006; Gelabert vd., 2011). Mevcut çalışmada özellikle Ailesel Eleştiri ile Benlik Saygısı (r=-.48; <0.01) arasında ve Davranışlardan Şüphe ile Benlik Saygısı (r=-.49; <0.01) arasında güçlü negatif korelasyonlar bulunmuştur. Benlik Saygıs1 değişkeni, mükemmeliyetçilik boyutlarından Düzen ve Kişisel Standartlar boyutları ile pozitif diğer tüm boyutlar (Ailesel Beklenti, Ailesel Eleştiri, Hatalara Aşırı İlgi, Davranışlardan Şüphe) ve Stres ile negatif ilişkili bulunmuştur. Stres ile Ailesel Beklenti, Hatalara Aşırı İlgi, Kişisel 
Standartlar ve Davranışlardan Şüphe pozitif ilişkili, Ailesel Eleştiri negatif ilişkili olarak bulunmuştur. Stresin Düzen ile korelasyonu ise anlamsızdır.

Mükemmeliyetçilik alt boyutları olan Hatalara Aşırı İlgi, Ailesel Eleştiri, Davranışlardan Şüphe, Düzen, Kişisel Standartlar ve Ailesel Beklenti ile Stres ve Benlik Saygısı arasındaki ilişkiler literatürdeki beklentilere uygun şekilde yapısal eşitlik modelleri ile modellenmiştir. Buna göre mükemmeliyetçiliğin Hatalara Aşırı İlgi, Davranışlardan Şüphe, Ailesel Eleştiri ve Ailesel Beklenti boyutlarının Benlik Saygısını negatif yönde etkilemesi, Düzen ve Kişisel Standartlar boyutlarının ise Benlik Saygısını pozitif yönde etkilemesi beklenmektedir. Mükemmeliyetçiliğin tüm boyutlarının Stresi negatif yönde etkilemesi ve son olarak Benlik Saygısının Stresi negatif yönde etkilemesi beklenmektedir. Şekil 1'de her bir boyuta ilişkin kurulmuş modeller ve tahmin sonuçları görülmektedir. Değişkenler arasındaki her bir ok aynı zamanda bir hipotezi temsil etmektedir. Kesikli oklar yolun anlamsız olduğunu göstermekte ve ilgili hipotezin desteklenmediği anlamına gelmektedir. Tüm modellerdeki katsayılar standardize edilmiş regresyon katsayılarıdır.

Şekil 1 (a)'daki yapısal eşitlik modeli incelendiğinde Hatalara Aşırı İlgi'nin Stres üzerinde hem direk hem dolaylı etkisi olduğu görülmektedir. Hatalara Aşırı İlgi'nin Stres üzerindeki standardize edilmiş toplam etkisi 0.31 olarak bulunmuştur. Bu etkinin $0.24(<0.05)$ 'ü direk etki ve 0.07'sı ise Benlik Saygısı üzerinden dolaylı etki olarak gerçekleşmiştir. Hatalara Aşırı İlgi'nin Benlik Saygısı üzerindeki direk etkisi $-0.46(<0.01)$ olarak hesaplanmıştır. Mükemmeliyetçilik boyutlarından Hatalara Aşırı İlgi Benlik Saygısı üzerinde negatif bir etkiye sahiptir. Hatalara Aşırı İlgi'deki bir birimlik standart sapmalık değişim Benlik Sayısını 0.46 standart sapma azaltmaktadır. Benlik Saygısının Stres üzerindeki etkisini gösteren standardize edilmiş yol katsayısı $-0.14 \quad(<0.01)$ olarak bulunmuştur. Modeldeki tüm yol katsayıları istatistiksel olarak anlamlıdır. Modele ilişkin hesaplanan uyum indeksleri $\left(\mathrm{X}^{2} / \mathrm{df}=2.01\right.$; $\mathrm{CFI}=0.88$; GFI=0.86; RMSEA=0.05; SRMR=0.07) kabul edilebilir uyum sınırları içinde yer almaktadır.

Şekil 1 (b)'de yer alan Ailesel Eleştiri'nin Benlik Saygısı üzerindeki direk etkisi -0.62 $(<0.01)$ ve Benlik Saygısının Stres üzerindeki etkisi -0.26 (<0.01) olarak bulunmuştur. Ailesel Eleştiri'nin Stres üzerinde direk etkisi gözlenmemiştir. Bu yol istatistiksel olarak anlamsızdır ve modelde kesikli ok ile gösterilmiştir. Ailesel Eleştiri'nin Stres üzerindeki etkisi Benlik Saygısı aracılı̆̆ıyla dolaylı olarak gerçekleşmektedir. Ailesel Eleştiri'nin Stres üzerindeki standardize edilmiş dolaylı etkisi 0.16 olarak bulunmuştur. Ailesel Eleştiri'nin bir standart sapma artması Stresin 0.16 standart sapma artmasına sebep olacaktır. Bu sonuç Ailesel Eleştiri'nin, Benlik Saygısı aracıllğı ile Stres üzerinde arttırıcı bir etkisi olduğunu göstermektedir. Modele ilişkin hesaplanan uyum indeksleri $\mathrm{X}^{2} / \mathrm{df}=1.99 ; \mathrm{CFI}=0.91$; $\mathrm{GFI}=0.88$; RMSEA $=0.05$; SRMR $=0.07$ olarak bulunmuştur.

Şekil 1 (c)'de modelde Davranışlardan Şüphe'nin Stres üzerindeki standardize edilmiş toplam etkisi $0.34(<0.01)$, Benlik Saygısı üzerindeki standardize edilmiş toplam etkisi -0.65 $(<0.01)$ olarak bulunmuştur. Bu modelin ilginç olan bulgusu Stres ve Benlik Saygısı arasındaki yolun anlamsızlaşmasıdır. Mükemmeliyetçiliğin Davranışlardan Şüphe boyutu hem Stres hem Benlik Saygısı değişkenlerini anlamlı şekilde etkilerken ikisi arasındaki yolun anlamsızlaşmasına neden olmuştur. Bu boyut modele dahil edildiğinde Benlik Saygısı $\left(\mathrm{R}^{2}=0.43\right)$ 
ve Stres $\left(\mathrm{R}^{2}=0.12\right)$ değişkenlerinin açıklanan varyanslarında da artış gözlenmiştir. Modelin uyum iyiliği değerleri şöyledir; $\mathrm{X}^{2} / \mathrm{df}=2.04 ; \quad \mathrm{CFI}=0.90 ; \quad \mathrm{GFI}=0.88 ; \quad \mathrm{RMSEA}=0.05$; SRMR $=0.07$.

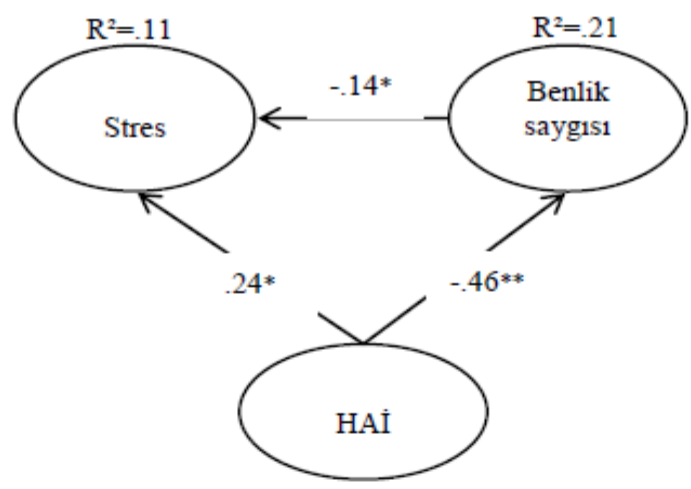

$X^{2} / \mathrm{df}=2.01 ; \mathrm{CFI}=0.88 ; \mathrm{GFI}=0.86 ; \mathrm{RMSEA}=0.05$; $\mathrm{SRMR}=0.07$

(a)

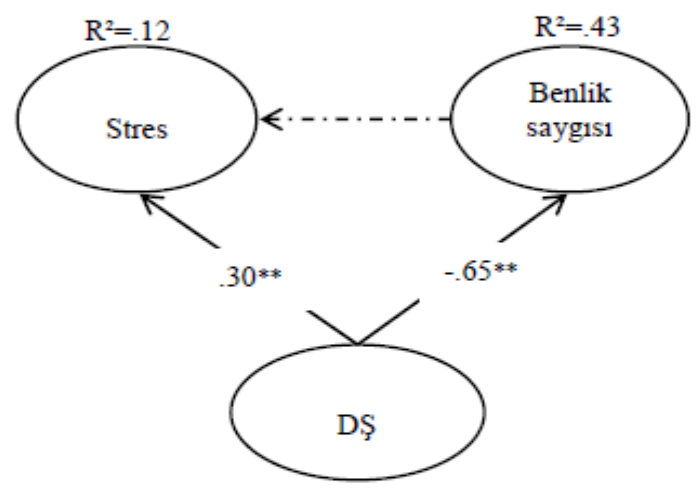

$X^{2} / \mathrm{df}=2.04 ; \mathrm{CFI}=0.90 ; \mathrm{GFI}=0.88 ; \mathrm{RMSEA}=0.05$; $\mathrm{SRMR}=0.07$

(c)

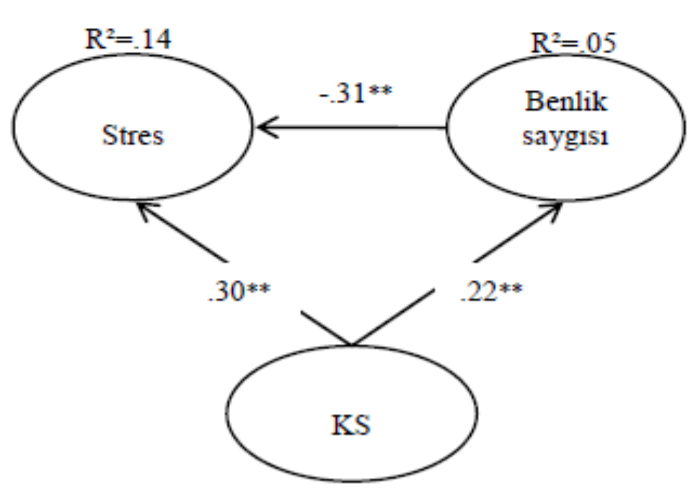

$X^{2} / \mathrm{df}=2.02 ; \mathrm{CFI}=0.89 ; \mathrm{GFI}=0.87 ; \mathrm{RMSEA}=0.05$; $\mathrm{SRMR}=0.07$

(e)

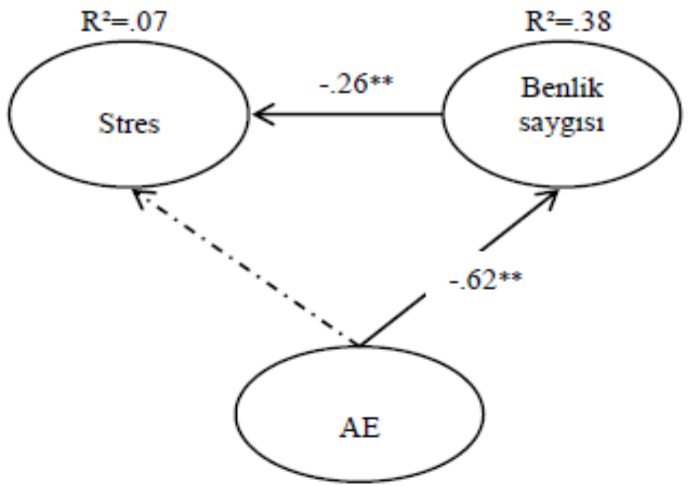

$X^{2} / \mathrm{df}=1.99 ; \mathrm{CFI}=0.91 ; \mathrm{GFI}=0.88 ; \mathrm{RMSEA}=0.05$; $\mathrm{SRMR}=0.07$

(b)

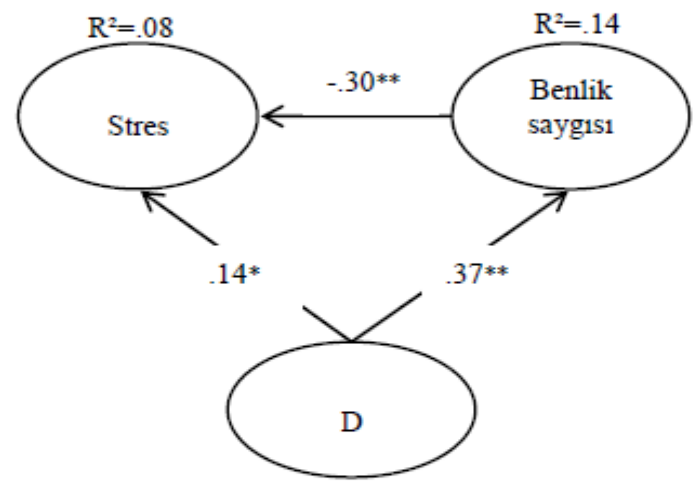

$X^{2} / \mathrm{df}=2.11 ; \mathrm{CFI}=0.90 ; \mathrm{GFI}=0.87 ; \mathrm{RMSEA}=0.05 ;$ $\mathrm{SRMR}=0.07$

(d)

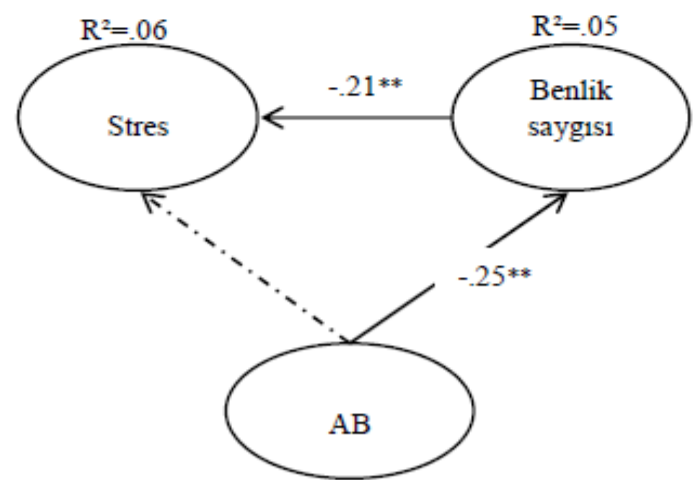

$X^{2} / \mathrm{df}=2.02 ; \mathrm{CFI}=0.90 ; \mathrm{GFI}=0.88 ; \mathrm{RMSEA}=0.05$; $\mathrm{SRMR}=0.07$

(f)

Not: AB: Ailesel Beklentiler, D: Düzen; AE: Ailesel Eleştiri; HAi: Hatalara Aşın İgi; KS: Kişisel Standartlar; DŞ: Davramışlardan Şüphe Şekil 1. Mükemmeliyetçilik alt boyutlan ile kurulan yapısal eşitlik modelleri $\left({ }^{*} p<0.05 ; * * \vec{p}<0.01\right)$ 
Şekil 1 (d)'de mükemmeliyetçiliğin Düzen boyutu ile ilgili model incelenmiştir. Bu modelde Düzen'nin Benlik Saygısı üzerinde $0.37(<0.01)$ pozitif etkisi olduğu görülmektedir. Düzen'nin Stres üzerinde standardize edilmiş direk etkisi $0.14(<0.05)$ olarak bulunmuştur. Düzen'nin Benlik Saygısı aracılığıyla Stres üzerinde dolaylı bir etkisi de söz konusudur. Düzen'nin Stres üzerindeki standardize edilmiş dolaylı etkisi $-0.11 \quad(<0.01)$ 'dir. Benlik Saygısı'nın Stres üzerindeki direk etkisi $(-0.30 ;<0.01)$ bu modelde de gözlenmektedir. Modele ilişkin uyum indeksleri $\mathrm{X}^{2} / \mathrm{df}=2.11 ; \mathrm{CFI}=0.90 ; \mathrm{GFI}=0.87 ; \mathrm{RMSEA}=0.05 ; \mathrm{SRMR}=0.07$ olarak elde edilmiştir.

Şekil 1 (e)'de Kişisel Standartlar'ın Benlik Baygısı $(0.22 ;<0.01)$ ve Stres $(0.30 ;<0.01)$ üzerinde direk etkilere sahip olduğu görülmektedir. Aynı zamanda Kişisel Standartlar'ın Stres üzerinde dolaylı etkisi de bulunmaktadır. Benlik Saygısı üzerinden gerçekleşen bu dolaylı etkinin standardize edilmiş değeri $-0.07 \quad(<0.01)$ olarak bulunmuştur. Dolayısıyla Kişisel Standartlar'ın Stres üzerindeki standardize edilmiş toplam etkisi 0.23 olarak gerçekleşmektedir. Kişisel Standartlar'ın Stres üzerindeki direk etkisi pozitif dolaylı etkisi ise negatiftir. Bu modelde Benlik Saygısının Stres üzerdeki standardize edilmiş direk etkisi -0.31 (<0.01)'dir. Modele ilişkin uyum indeksleri $\mathrm{X}^{2} / \mathrm{df}=2.02$; $\mathrm{CFI}=0.89$; $\mathrm{GFI}=0.87$; RMSEA $=0.05$; $\mathrm{SRMR}=0.07$ olarak bulunmuştur.

Şekil 1 (f)'de Ailesel Beklentiler'nin Benlik Saygısı üzerindeki standardize edilmiş toplam etkisi $-0.21 \quad(<0.01)$ olarak bulunmuştur. Bu değişkenleri etkileyen başka etki olmadığından bu değer aynı zamanda standardize edilmiş direk etki katsayısıdır. Ailesel Beklenti'nin Stres üzerindeki direk etkisi anlamsız bulunmuştur. Ailesel Beklenti'nin Stres üzerindeki dolaylı etkisi 0.05 olarak gerçekleşmiştir. Benlik Saygısı'nın Stres üzerindeki standardize edilmiş toplam etkisi aynı zamanda direk etkisi ise $-0.25(<0.01)$ 'tir. Model uyum indeksleri $\mathrm{X}^{2} / \mathrm{df}=2.02 ; \mathrm{CFI}=0.90 ; \mathrm{GFI}=0.88 ; \mathrm{RMSEA}=0.05$; $\mathrm{SRMR}=0.07$ olarak elde edilmiştir.

\section{Tartışma ve Sonuç}

$\mathrm{Bu}$ çalışmanın bulguları mükemmeliyetçilik boyutlarının -seçilmiş değişkenler (stres ve benlik saygısı) üzerinden- olumlu ve olumsuz etkileriyle ilgili kapsamlı bir tablo sunmaktadır. Hatalara Aşırı İlgi, Davranışlardan Şüphe, Ailesel Eleştiri ve Ailesel Beklenti değişkenleri ile stres, anksiyete, depresyon gibi negatif duygudurumları arasındaki ilişkilerin incelendiği çalışmalar ile bu çalışmadan elde edilen bulgular örtüşmektedir (Bieling vd., 2004; Frost vd., 1990; Saboonchi ve Lundh, 1997). Mükemmeliyetçiliğin bu boyutları maladaptif yönelimi işaret etmekte ve olumsuz olarak değerlendirilmektedir. $\mathrm{Bu}$ çalışmadan elde edilen sonuçlar bu alt mükemmeliyetçilik boyutlarının stres üzerinde arttırıcı bir etkisi olduğunu göstermektedir. Benzer şekilde bu çalışmada Düzen ve Kişisel Standartlar alt boyutlarının da stres üzerinde arttırıcı bir etki yarattığı sonucuna ulaşılmıştır. Ancak bu iki boyut maladaptif olarak değerlendirilmemektedir (Frost, 1993). Bunun nedeni yukarıda da bahsedildiği gibi bu boyutların olumlu etkileridir. Bieling ve diğerleri (2004) çalışmasında Düzen ve Kişisel Standartlar boyutlarını olumlu çabalar (Positive striving) olarak ele alınmış ve stres ile korelasyonları pozitif bulunmuştur. Aynı zamanda diğer dört alt boyut (Hatalara Aşırı İlgi, Davranışlardan Şüphe, Ailesel Eleştiri ve Ailesel Beklenti) maladaptif (Maladaptive evaluative concerns) olarak değerlendirilmiş ve yine stres ile korelasyonları pozitif bulunmuştur (Bieling vd., 2004, s.1380). Bu bulgu mevcut çalışmayı destekler niteliktedir. Chang ve arkadaşları 
(2004) ve Ashby ve arkadaşları (2012) tarafından yapılan çalışmasında adaptive ve maladaptive mükemmeliyetçilik ile algılanan stres arasındaki ilişkiler farklı sonuçlar vermiştir. Chang ve arkadaşlarının (2004) çalışmasında maladaptive mükemmeliyetçilik ile stres pozitif ilişki bulunurken adaptive mükemmeliyetçilik ile stres arasında anlamlı ilişki bulunamamıştır. Ashby ve arkadaşlarının (2012) çalışmasında adaptive mükemmeliyetçilik ile algılanan stres negatif ilişkili bulunurken, maladaptive mükemmeliyetçilik ile algılanan stres pozitif ilişkili bulunmuştur. Mevcut çalışmada mükemmeliyetçilik alt boyutları ile stres pozitif ilişkili bulunmuştur. Ailesel Eleştiri ve Ailesel Beklenti alt boyutları ile stres arasında ise anlamlı ilişki bulunamamıştır.

Mükemmeliyetçiliğin Düzen ve Kişisel Standartlar boyutları Benlik Saygısı üzerinde pozitif etki göstermiştir. Ancak bunun aksine Hatalara Aşırı İlgi ve Davranışlardan Şüphe boyutları Benlik Saygısını negatif yönde etkilemiştir. Benlik Saygısını negatif yönde etkileyen diğer iki boyut ise Ailesel Eleştiri ve Ailesel Beklenti boyutlarıdır. Bu boyutlarla kurulan modellerdeki farklılık ise Stres üzerindeki direk etkilerinin anlamsız bulunmasıdır. Bu boyutların stres üzerindeki etkisi Benlik Saygısı üzerinden dolaylı olarak gerçekleşmiştir. Yapılan bazı çalışmalarda da benlik saygısının aracılık etkisi gösterdiği ampirik olarak ortaya konmuştur (Preusser, vd., 1994; Rice vd., 1998). Bu bulgular özellikle bireylerin benlik saygılarını ilk edindikleri yerlerden birinin aile ortamı olduğu düşünüldüğünde dikkate değerdir. Ailesel beklenti ve eleştiriler bireyin benlik saygısını etkilemektedir. Bu çalışmada Ailesel Eleştiri ve Ailesel Beklenti için kurulan modellerde stres yolunun anlamsız bulunması, mevcut örneklemde Ailesel Eleştiri ve Ailesel Beklentilerin etkisinin Benlik Saygısı aracılığıyla ortaya çıktığını göstermektedir. Frost ve diğerlerinden (1990) farklı olarak Stallman ve Hurst (2011) çalışmasında Ailesel Eleştiri ve Ailesel Beklenti boyutlarının tek bir boyut olarak kullanılması gerektiğini söylemiştir. Mevcut çalışmada Ailesel Eleştiri ve Ailesel Beklenti boyutları ile kurulan iki modelin de benzer sonuçlar vermesi bu iki boyutun tek bir boyut olarak ele alınabilir olduğunu düşündürmektedir.

Mükemmeliyetçiliğin boyutları ile benlik saygısının ilişkili bulunduğu çalışmalar (Ashby vd., 2006; Rice, vd., 2007; Stumpf ve Parker, 2000) söz konusudur. Ancak mükemmeliyetçilik alt boyutları ile benlik saygısı arasında bulunan bazı bulgular çalışmalar arasında farklılık göstermektedir. Mevcut çalışmadan elde edilen bulguların aksine Gotwals ve diğerleri (2003) atletlerle ilgili çalışmasında Kişisel Standartlar, Düzen ve Ailesel Beklenti ile Benlik Sayısı arasında anlamlı ilişki bulunamamışlardır (Gotwals vd., 2003, s. 28). Cheng ve diğerlerinin (1999) çalışmasında benzer şekilde Hatalara Aşırı İlgi, Ailesel Eleştiri, Ailesel Beklenti, Davranışlardan Şüphe ve Düzen boyutları ile Benlik Saygısı anlamlı şekilde ilişkili iken Kişisel Standartlar ile Benlik Saygısı arasındaki korelasyon anlamsız bulunmuştur. Stres ile Düzen boyutu arasındaki korelasyon hariç diğer değişkenler Stres ile anlamlı şekilde ilişkilidir (Cheng vd., 1999, s.1057).

$\mathrm{Bu}$ çalışmada kurulan yapısal eşitlik modellerinde oklarla gösterilen hipotezlerin çoğu, analizler sonucu elde edilen bulgularla desteklenmiştir. Ailesel Eleştiri ve Ailesel Beklenti boyutları ile Stres arasındaki direk etkiyi gösteren hipotezler veri ile desteklenen sonuçlar üretmemiştir. $\mathrm{Bu}$ yollar istatistiksel olarak anlamsız bulunmuştur ve bu boyutların etkisini 
Benlik Saygısı aracılığıyla gösterdiği sonucuna ulaşılmıştır. Bir diğer ilgi çekici sonuç ise Davranışlardan Şüphe alt boyutunun Benlik Saygısı ve Stresi anlamlı şekilde etkilerken, Benlik Saygısı ve Stres arasındaki yolu anlamsızlaştırmasıdır. Kurulan tüm modellerde Benlik Saygısı ve Stres arasında anlamlı etki bulunmuş ancak Davranışlardan Şüphe modelinde bu etki anlamsızlaşmıştır. Mevcut örneklemde Davranışlardan Şüphe Benlik Saygısını negatif yönde Stresi pozitif yönde etkilemektedir. Bu bulgu Davranışlardan Şüphe kavramının Benlik Saygısı ile benzer ancak tersi bir kavram gibi davrandığını düşündürmektedir.

Mükemmeliyetçilik alt boyutları bu çalışmanın bulguları ile ikiye ayrılacak olursa Benlik Saygısı üzerinde pozitif etkisi olan boyutlar Kişisel Standartlar ve Düzen, negatif etkisi olan boyutlar Hatalara Aşırı İlgi, Ailesel Eleştiri, Ailesel Beklenti ve Davranışlardan Şüphe'dir. Stresi arttırıcı yönde direk etkisi olan mükemmeliyetçilik boyutları ise Hatalara Aşırı İlgi, Davranışlardan Şüphe, Düzen ve Kişisel Standartlar'dır. Olumlu bir kavram olarak çalışmaya dahil edilen Benlik Saygısı üzerinde arttırıcı etkisi olan Kişisel Standartlar ve Düzen, olumsuz bir kavram olarak ele alınan Stres için de arttırıcı bir etki yaratmaktadır. Bu bulgu akla mükemmeliyetçiliğin olumlu olarak değerlendirilen boyutlarının olumsuz etkilerinin de olabileceğini getirmektedir. Olumlu olarak değerlendirilen boyutların olumsuz kavramlarla pozitif ilişkiler içinde bulunması daha detaylı incelenmesi gereken bir noktadır.

Çalışmanın amacı doğrultusunda katılımcıların çok boyutlu mükemmeliyetçilik algısı ve bu algının Stres ve Benlik Saygısı ile olan ilişkileri ele alınmıştır. Bu çalışmanın bulguları daha önceki çalışmalarda elde edilen sonuçlarla desteklenmesinin yanı sıra mevcut örneklem için mükemmeliyetçiliğin tek boyutlu yapısından ziyade çok boyutlu yapısının daha fazla bilgi içerdiğine yönelik kanıtlar sunmaktadır. Mükemmeliyetçiliğin farklı boyutlarının stres ve benlik saygısı üzerinde farklı etkileri olması mükemmeliyetçiliğin çok boyutlu bir yap1 olarak değerlendirilmesinin daha iyi sonuçlar vereceğini göstermektedir.

$\mathrm{Bu}$ çalışmanın gerçekleştirilmesinde bazı sınırlılıklar bulunmaktadır. Çalışmada çapraz kesit verisi ile çalışılmıştır. Veriler anket yolu ile toplanmış ve dolayısıyla kişilerin detaylı ve güvenilir bilgiler verdikleri kabul edilmiştir. Çalışmada tek bir örneklem kullanılmış ve tüm sonuçlar bu örneklem üzerinden yorumlanmıştır.

Mükemmeliyetçilik Adler'in (1956) de belirttiği gibi doğuştan gelen bir kavram olarak ele alındığında insan hayatında önemli bir yeri vardır. Bu çalışmanın bulguları doğrultusunda pozitif psikolojik işleyişin geliştirilmesinde mükemmeliyetçilik kavramının anlaşılmasının önemli olduğunu söylemek mantıklı olacaktır. Özellikle genç yaştaki bireylerin mükemmeliyetçilik kavramını doğru anlayarak mükemmeliyetçilik algılarını pozitif olarak yönlendirmeleri ve bu konuda desteklenmeleri sağlıklı yaşantılar geliştirmelerine katk1 sağlayacaktır. Mükemmeliyetçilik ile ilgili yapılacak çalışmalarda farklı örneklemler kullanılarak özellikle Ailesel Eleştiri ve Ailesel Beklenti alt boyutlarının etkilerinin nasıl olduğunu incelenebilir. Aynı zamanda mükemmeliyetçiliğin alt boyutlarının değişkenler üzerinde pozitif/negatif etki göstermeleri stres ve benlik saygısı dışında farklı değişkenlerle modellenerek detaylandırılabilir. Bu çalışmalar hem mükemmeliyetçiliğin adaptif/maladaptif yönelimine ilişkin sonuçlar üretecek hem de farklı değişkenlerle direk ya da dolaylı ilişkilerini ortaya koyacaktır. Aynı zamanda bu ilişkilerin detaylandırılması mükemmeliyetçilik algısının 
anlaşılarak daha doğru tanımlanmasına ve farklı kültürlerdeki işleyişinin doğru şekilde anlaşılmasına da fayda sağlayacaktır. 


\section{Kaynakça}

Adler, A. (1956). The neurotic disposition. In H. L. Ansbacher \& R. R. Ansbacher (Eds.), The individual psychology of Alfred Adler (pp. 239-262). New York: Harper.

Ashby, J. S., Rice, K. G. \& Martin, J. L. (2006). Perfectionism, shame, and depressive symptoms. Journal of Counseling \& Development, 84(2), 148-156.

Ashby, J. S., Noble, C. L., \& Gnilka, P. B. (2012). Multidimensional perfectionism, depression, and satisfaction with life: Differences among perfectionists and tests of a stress-mediation model. Journal of College Counseling, 15(2), 130-143.

Bieling, P. J., Israeli, A. L. \& Antony, M. M. (2004). Is perfectionism good, bad, or both? Examining models of the perfectionism construct. Personality and individual differences, 36(6), 1373-1385.

Bilgel, N. ve Bayram, N. (2009). Depresyon anksiyete stres ölçeğinin (DASS-42) Türkçeye uyarlanmış şeklinin psikometrik özellikleri. Nöropsikiyatri Arşivi, 47, 118-126.

Burns, D. D. (1980). The perfectionist's script for self-defeat. Psychology Today, November, 34-51.

Camadan, F. ve Yüksel, G. (2012). Türk Ortaöğretim Öğrencilerinde Mükemmeliyetçilik. Gaziantep University Journal of Social Sciences, 11(3), 701-714.

Chang, E. C., Watkins, A., \& Banks, K. H. (2004). How Adaptive and Maladaptive Perfectionism Relate to Positive and Negative Psychological Functioning: Testing a Stress-Mediation Model in Black and White Female College Students. Journal of Counseling Psychology, 51(1), 93.

Cheng, S. K., Chong, G. H. \& Wong, C. W. (1999). Chinese frost multidimensional perfectionism scale: A validation and prediction of self-esteem and psychological distress. Journal of Clinical Psychology, 55(9), 1051-1061.

Cox, B. J., Enns, M. W. \& Clara, I. P. (2002). The multidimensional structure of perfectionism in clinically distressed and college student samples. Psychological assessment, 14(3), 365.

Çam, Z., Deniz, K. Z. ve Kurnaz, A. (2014). Okul tükenmiş̧liği: Algıllanan sosyal destek, mükemmeliyetçilik ve stres değiş̧kenlerine dayalı bir yapısal eşitlik modeli sınaması. Eğitim ve Bilim, 39(173).

Çuhadaroglu, F. (1985). Adolesanlarda benlik saygısl. Yayımlanmamis Doktora Tezi. Hacettepe Üniversitesi, Sosyal Bilimler Enstitüsü, Ankara.

D'Souza, F., Egan, S. J. \& Rees, C. S. (2011). The relationship between perfectionism, stress and burnout in clinical psychologists. Behaviour Change, 28(1), 17-28.

Flett, G. L., Hewitt, P. L., Blankstein, K. R. \& Koledin, S. (1991). Dimensions of perfectionism and irrational thinking. Journal of Rational-Emotive and Cognitive-Behavior Therapy, 9(3), 185-201.

Frost, R. O., Heimberg, R. G., Holt, C. S., Mattia, J. I. \& Neubauer, A. L. (1993). A comparison of two measures of perfectionism. Personality and individual differences, 14(1), 119-126.

Frost, R. O., Marten, P., Lahart, C. \& Rosenblate, R. (1990). The dimensions of perfectionism. Cognitive therapy and research, 14(5), 449-468.

Gelabert, E., García-Esteve, L., Martín-Santos, R., Gutiérrez, F., Torres, A., \& Subirà, S. (2011). Psychometric properties of the Spanish version of the Frost Multidimensional Perfectionism Scale in women. Psicothema, 23(1).

Gotwals, J. K., Dunn, J. G. \& Wayment, H. A. (2003). Self-Esteem in Intercollegiate Athletes. Journal of Sport Behavior, 26, 1.

Hamachek, D. E. (1978). Psychodynamics of normal and neurotic perfectionism. Psychology, 15, 27-33.

Hawkins, C. C., Watt, H. M., \& Sinclair, K. E. (2006). Psychometric properties of the Frost Multidimensional Perfectionism Scale with Australian adolescent girls: Clarification of 
multidimensionality and perfectionist typology. Educational and psychological measurement, 66(6), 1001-1022.

Hewitt, P. L. \& Flett, G. L. (1991). Perfectionism in the self and social contexts: conceptualization, assessment, and association with psychopathology. Journal of personality and social psychology, $60(3), 456$.

Hollender, M. H. (1965). Perfectionism. Comprehensive Psychiatry, 6, 94-103.

Kağan, M. (2011). Frost Çok Boyutlu Mükemmeliyetçilik Ölçeği'nin Türkçe Formunun Psikometrik Özellikleri. Anadolu Psikiyatri Dergisi, 12(3), 192-197.

Leana-Tascilar, M. Z. ve Kanli, E. (2014). Investigation of perfectionism and self-esteem scores of gifted and average students. Egitim Bilimleri Fakultesi Dergisi, 47(2), 1.

Mert, A. (2019). Üniversite öğrencilerinin sosyal kaygı, mükemmelliyetçilik ve değerler arasındaki ilişkinin açıklanmasına yönelik bir model çalışması. Mehmet Akif Ersoy Üniversitesi Ĕgitim Fakültesi Dergisi, 49, 276-301.

Mısırl1-Taşdemir, Ö. ve Özbay, Y. (2003). Üstün Yetenekli Çocuklarda, Mükemmeliyetçilik, Sınav Kaygısı, Benlik Saygısı, Kontrol Odă̆l, Öz Yeterlilik ve Problem Çözme Becerileri Arasındaki İlişkinin Incelenmesi. Yayınlanmamış yüksek lisans tezi, Karadeniz Teknik Üniversitesi, Sosyal Bilimler Enstitüsü, Trabzon.

Özgüngör, S. (2003). Mükemmeliyetçilik ve özerklik destekleyici davranışların amaç tarzları ile ilişkisi. Ĕ̈itim ve Bilim, 28(127).

Preusser, K. J., Rice, K. G. \& Ashby, J. S. (1994). The role of self-esteem in mediating the perfectionismdepression connection. Journal of College Student Development, 35(2), 88-93.

Rice, K. G., Ashby, J. S. \& Slaney, R. B. (1998). Self-esteem as a mediator between perfectionism and depression: A structural equations analysis. Journal of counseling psychology, 45(3), 304.

Rice, K. G., Ashby, J. S. \& Slaney, R. B. (2007). Perfectionism and the five-factor model of personality. Assessment, 14(4), 385-398.

Rosenberg, M. (1965). Rosenberg self-esteem scale (RSE). Acceptance and commitment therapy. Measures package, 61, 52.

Smith, M. M., Saklofske, D. H., Stoeber, J., \& Sherry, S. B. (2016). The big three perfectionism scale: A new measure of perfectionism. Journal of Psychoeducational Assessment, 34(7), 670-687.

Stallman, H. M., \& Hurst, C. P. (2011). The factor structure of the frost multidimensional perfectionism scale in university students. Australian Psychologist, 46(4), 229-236.

Stumpf, H., \& Parker, W. D. (2000). hierarchical structural analysis of perfectionism and its relation to other personality characteristics. Personality and individual differences, 28(5), 837-852. 


\section{Extended Abstract}

\section{Introduction}

Perfectionism can be considered as an indicator of the emotions of individuals in the process of reaching the best. It is important to understand the concept of perfectionism in the development of positive psychological functioning. Especially the perceptions of perfectionism of the students who continue their education will affect their state of their emotions. Indirectly, it is also thought that it may affect other factors in educational life.

Although perfectionism was first considered as a one-dimensional structure, its multidimensional structure was revealed in later periods. Perfectionism is defined as a sixdimensional structure by Frost et al. (1990). These dimensions are named organization, concern about mistakes, parental expectation, parental criticism, and doubts about actions and personnel standards. Perfectionism is seen as a risk factor for negative emotions such as depression, anxiety, stress, and burnout. On the other hand, it is thought that the perception of perfectionism can be considered positive with some dimensions. Based on the discussions at this point, the question of whether the effects of perfectionism dimensions on the concepts that can be evaluated as positive and negative are examined. In the current study, the concept of perfectionism is discussed together with students' self-esteem and stress. The aim is to examine the positive (self-esteem) and negative (stress) variables together with the sub-dimensions of perfectionism and to examine the positive / negative effects. It is aimed to make inferences about the direction of perfectionism sub-dimensions.

\section{Method}

The sample of this study is limited to only university students in accordance with purpose. The convenience sampling method was used. Participants answered a questionnaire form consisting of demographic questions and scales (Frost Multidimensional Perfectionism Scale, Rosenberg Self-Esteem Scale and Depression Anxiety Stress Scale). The sample of the study, which consisted of 367 forms, was consisted of 222 female students and 145 male students. The students were between the ages of 18-28 and the mean age for the whole sample was 21.81 ( \pm 2.37). Turkish university students sample dealt with this objective, positive and negative, respectively; self-esteem and stress variables are discussed and their relationships with subdimensions of perfectionism are modeled. Frost Multidimensional Perfectionism Scale was used and estimations were made with structural equation models that produced stronger estimation results by taking into account measurement errors.

\section{Findings}

Cronbach's Alpha values were used to calculate the internal consistency of the scales used in the study. Cronbach's Alpha values were found to be greater than 0.70 for all dimensions. The relationships between the variables were summarized by the correlation table and found to be appropriate for prior expectations. Separate models for perfectionism dimensions were estimated with structural equation model. It was found that university students' perceptions of 
perfectionism had statistically significant effects on stress and self-esteem. It was found that the four dimensions of perfectionism (organization, concern about mistakes, doubts about actions and personnel standards) directly affected stress and also all dimensions directly affected (organization, concern about mistakes, parental expectation, parental criticism, doubts about actions and personnel standards) self-esteem. At the same time, it has been shown that selfesteem is mediating for some perfectionism sub-dimensions. The findings of this study were supported by previous studies. The "organization" and "personal standards" dimensions of perfectionism showed a positive effect on students' self-esteem. On the other hand, "concern about mistakes" and "doubts about actions" dimensions have negatively affected self-esteem. The other two dimensions that negatively affect self-esteem are "parental expectation" and "parental criticism" dimensions. The difference in the models established with these dimensions is that the direct effects on stress are meaningless. The effect of these dimensions on stress was indirectly occurred through self-esteem. Another quirky result is that the "doubts about actions" sub-dimension significantly affected self-esteem and stress but it made the path between selfesteem and stress was meaningless. A significant effect was found between self-esteem and stress on all models, but this effect was meaningless in the "doubts about actions" subdimension model.

\section{Conclusion}

In current study's findings provide evidence that the multidimensional structure rather than the one-dimensional structure of perfectionism contains more information. Studies on multidimensional perfectionism will produce results on both adaptive/maladaptive structures and will reveal direct or indirect relationships with different variables. At the same time, the elaboration of these relations will help to understand the perception of perfectionism more accurately and will help to understand correctly in different cultures. It is especially for young people to be able to correctly understand the concept of perfectionism and to direct their perceptions of perfectionism positively and also it is important to be supported in this regard. 